\title{
Laboratory stand for definition the filtration properties of coal seams
}

\author{
Oleg Tailakov*", Evgeniy Utkaev, Alexey Smyslov, and Sergey Kolesnichenko \\ Federal Research Center for Coal and Coal Chemistry SB RAS, 650000, Kemerovo, Russia
}

\begin{abstract}
To define the filtration properties of rocks, various physicochemical methods are used, among which laboratory studies can be distinguished $[1,2]$. Determination of permeability in laboratory conditions is the main physical and technical study of the filtration properties of rocks.
\end{abstract}

\section{Introduction}

Gas permeability is a property of a porous medium that characterizes its ability to pass gas through itself under gas pressure gradient influence. Gas permeability is an indicator characterizing the conductivity of a porous medium in relation to a gas of a certain viscosity $[4,5]$. Per a gas permeability unit of measurement $\left(\mathrm{m}^{2}\right)$ the gas permeability of a porous medium sample with a length of $1 \mathrm{~m}$ and an area of $1 \mathrm{~m}^{2}$, through which, at $1 \mathrm{~Pa}$ a pressure drop, the $\mathrm{m}^{3} / \mathrm{s}$ of gas with a viscosity of $1 \mathrm{~Pa} \cdot \mathrm{s}$ flows is taken. Determination of the gas permeability of coals, which, in contrast to porous media in natural gas deposits (porous sandstones, sands, etc.), have the ability to interact with sorption gases (sorbates), is complicated by sorption-desorption processes of a porous medium and therefore requires a special approach. The permeability of rocks can vary in the range from 0.1 to $1000 \mathrm{md}$ or more. The quality of rocks, determined by its permeability, is divided into 5 classes:

1 - very high permeability, permeability coefficient is over $1000 \mathrm{mD}$;

2 - good permeability, the permeability coefficient varies from 100 to $1000 \mathrm{mD}$;

3 - medium permeability, the coefficient of permeability varies from 10 to $100 \mathrm{mD}$;

4 - low permeability: the coefficient of permeability varies from 1 to $10 \mathrm{mD}$;

5 - impermeable, the coefficient of permeability is less than $1 \mathrm{mD}$;

Thus in Texas coal fields, permeability can reach up to $4,600 \mathrm{mD}$. At the same time, in the field in Lee County, Virginia, the reservoir permeability is $0.9 \mathrm{mD}$. The permeability of the developed coal seams, according to the study results of different researchers, in deposits of Karaganda coal basin varies from 0.0005 to $0.05 \mathrm{mD}$, for the coals of the Donetsk coal basin, the permeability varies from 0.01 to $58 \mathrm{mD}$ (while the gas permeability of grade $\mathrm{C}$ (coking coal), Lisichansk region, fluctuates within 1,113-1,330 mD), gas permeability for coals of the Kuznetsk coal basin varies from $0.005-66.4 \mathrm{mD}$ (while the permeability of the Polysaevsky and Nadbaikimsky seams ranges from 0.036 to $0.038 \mathrm{mD}$, and for the Breevsky and Tolmachevsky coal cseams it ranges from $0.005-0.0013 \mathrm{mD}$ ).

\footnotetext{
*Corresponding author: tailakov@uglemetan.ru
} 


\section{Main part}

To implement the research, coal samples were prepared in accordance with the requirements of GOST 26450.0-85 and GOST 26450.2-85 [6, 7].

Sampling requirements:

- to determine reservoir properties rock samples are taken using a core sampler, or in the form of pieces of arbitrary shape;

- when determining the absolute gas permeability, rock samples of the correct (cylindrical, cubic) shape are used;

- to determine the permeability during linear filtration, cylindrical samples with a diameter of $31 \mathrm{~mm}$ and a height of $30 \mathrm{~mm}$ are used.

To prepare samples of the correct geometric shape, carbide or diamond core bits and diamond wheels are used. After manufacturing, a laboratory number is applied to the sample with black ink and its orientation is marked with conventional signs.

In case a lateral surface of the core is damaged, which may occur during drilling and core removal, the outer layer is removed, or a cylindrical sample of the maximum size is made from the middle part of the core.

Determination of reservoir properties is made on samples dried to a constant weight at $(105 \pm 2){ }^{\circ} \mathrm{C}$ temperature in a drying cabinet. The main technical characteristics of the drying cabinet (ShS-80-01-SPU) are presented in Table 1.

Table 1. Main technical characteristics of the drying cabinet (ShS-80-01-SPU).

\begin{tabular}{|l|c|}
\hline \multicolumn{1}{|c|}{ Parameter name } & Value parameter for the cabinet \\
\hline Working chamber volume (L), not less & 80 \\
\hline Operating temperature range $\left({ }^{\circ} \mathrm{C}\right)$ & from 50 to 200 \\
\hline $\begin{array}{l}\text { Maximum temperature deviation at the control point of } \\
\text { the working chamber from the specified temperature } \\
\left({ }^{\circ} \text { C), not more. }\right.\end{array}$ & \pm 6 \\
\hline $\begin{array}{l}\text { Accuracy of maintaining the temperature in the } \\
\text { working chamber in the steady state, not worse }\left({ }^{\circ} \mathrm{C}\right)\end{array}$ & \pm 3 \\
\hline $\begin{array}{l}\text { Heating time to the maximum temperature }(\text { min) }), \text { not } \\
\text { more }\end{array}$ & 30 \\
\hline Time of continuous work ( h), not less & 16 \\
\hline Installed capacity (kW), not more & 1.6 \\
\hline $\begin{array}{l}\text { Overall dimensions of the cabinet (mm), not more: } \\
\text { depth } \\
\text { width } \\
\text { height }\end{array}$ & 626 \\
\hline $\begin{array}{l}\text { Working chamber dimensions (mm), not less: } \\
\text { width } \\
\text { depth } \\
\text { height }\end{array}$ & 680 \\
\hline Weight (kg), not more & 603 \\
\hline Average service life (years), not less & 560 \\
\hline
\end{tabular}

Equipment and tools to define reservoir properties - the installation for absolute gas permeability determination during stationary filtration is shown in Fig. 1. 


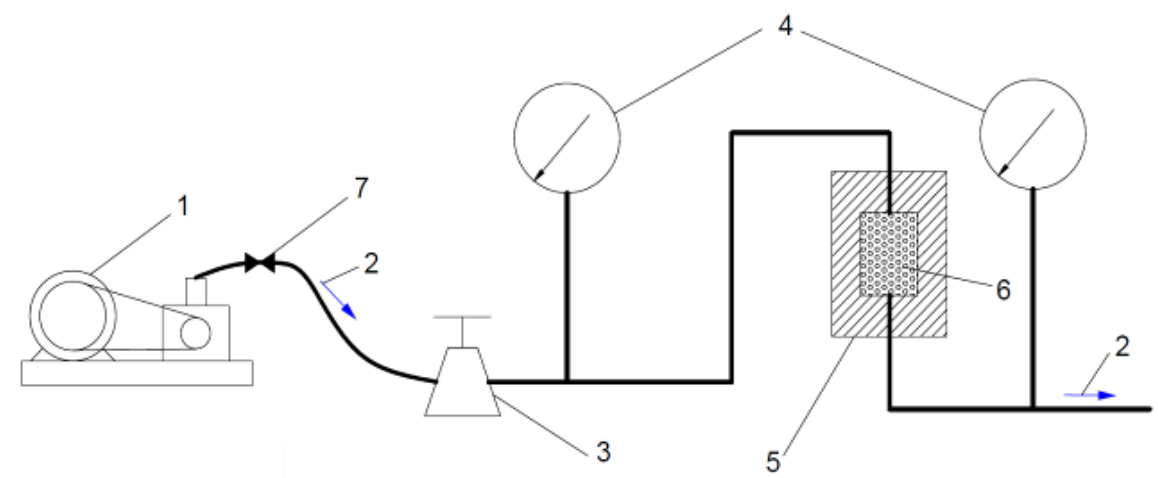

Fig. 1. Schematic representation of the installation for determination the absolute gas permeability coefficient: 1 - pressure source (compressor); 2 - direction of air migration; 3 - flow meter; 4 - pressure gauge; 5 - core holder; 6 - rock sample; 7 - valve.

The installation design ensures the availability of a pressure source, pressure regulator, core holder, pressure meters and is in conformity with the following requirements:

- during stationary filtration, a compressed air compressor becomes the source of pressure The gas is purified from water vapor and polluting dust using a filter;

- $\quad$ spring pressure gauges for accurate measurements are used to measure pressure;

- a volumetric flask and a stopwatch is used as a flow meter;

- in a core holder for linear filtration, the lateral surface of the sample is sheathed in a thin-walled heat-shrink tube.

Determination of the absolute permeability coefficient was carried out on 8 rock samples using a specialized stand.

Petrophysical samples were made by drilling out cores from pieces of rocks. The rocks had a layered and obliquely layered structure, brittle, which increased the risk of samples splitting into thin plates.

The production of petrophysical samples of cylindrical shape with $31 \times 30 \mathrm{~mm}$ dimensions was done by drilling out a cylinder from a piece of a rock sample and ends trimming using a diamond wheel. Drilling was carried out by a vertical drilling machine using diamond core bits of $31 \mathrm{~mm}$ inner diameter.

Table 2. Samples register of received rock samples.

\begin{tabular}{|c|c|}
\hline No. & Sampling depth (m) \\
\hline 1 & 23 \\
\hline 2 & 49 \\
\hline 3 & 51 \\
\hline 4 & 52 \\
\hline 5 & 68 \\
\hline 6 & 103 \\
\hline 7 & 137 \\
\hline 8 & 143 \\
\hline
\end{tabular}


The determination of the absolute gas permeability coefficient for stationary filtration was done with a linear direction of the air flow (Fig. 2). Measurement procedure includes:

1. With linear flow, a cylindrical sample is placed in the core holder (8). To do this, a sample is placed in the center in a specially prepared cylindrical iron ring and the empty space is filled with sealed (household) glue in order to eliminate leaks; gaskets are installed on the ring on both sides and tightened with metal plates and allowed to dry for at least 5 days. In case of leaks between the gaskets and the ring, it is necessary to disassemble the core holder, install new gaskets and tighten the plates again, check the tightness.

2. The compressor (6) is connected to the power supply (1) and creates operating pressure in the receiver (6).

3. The compressor is connected to the unit through a hose (4) and the differential pressure is adjusted.

4. Gas flow rate measurement through the sample with the pressure drop set up in the range (0.1-0.4) $\mathrm{MPa}$ is implemented.

5. Using the valve (3), the pressure is set, and the flow rate is changed by the rotameter (7).

6. Each measurement is logged for calculation.

7. After testing, it is necessary to lower the pressure to $0 \mathrm{MPa}$ using the valve (3), wait until all the air comes out through the outlet valve (9), then disconnect the hose (4) from the compressor (2) and release the pressure in the receiver (6).

8. Upon work completion, the power is turned off.

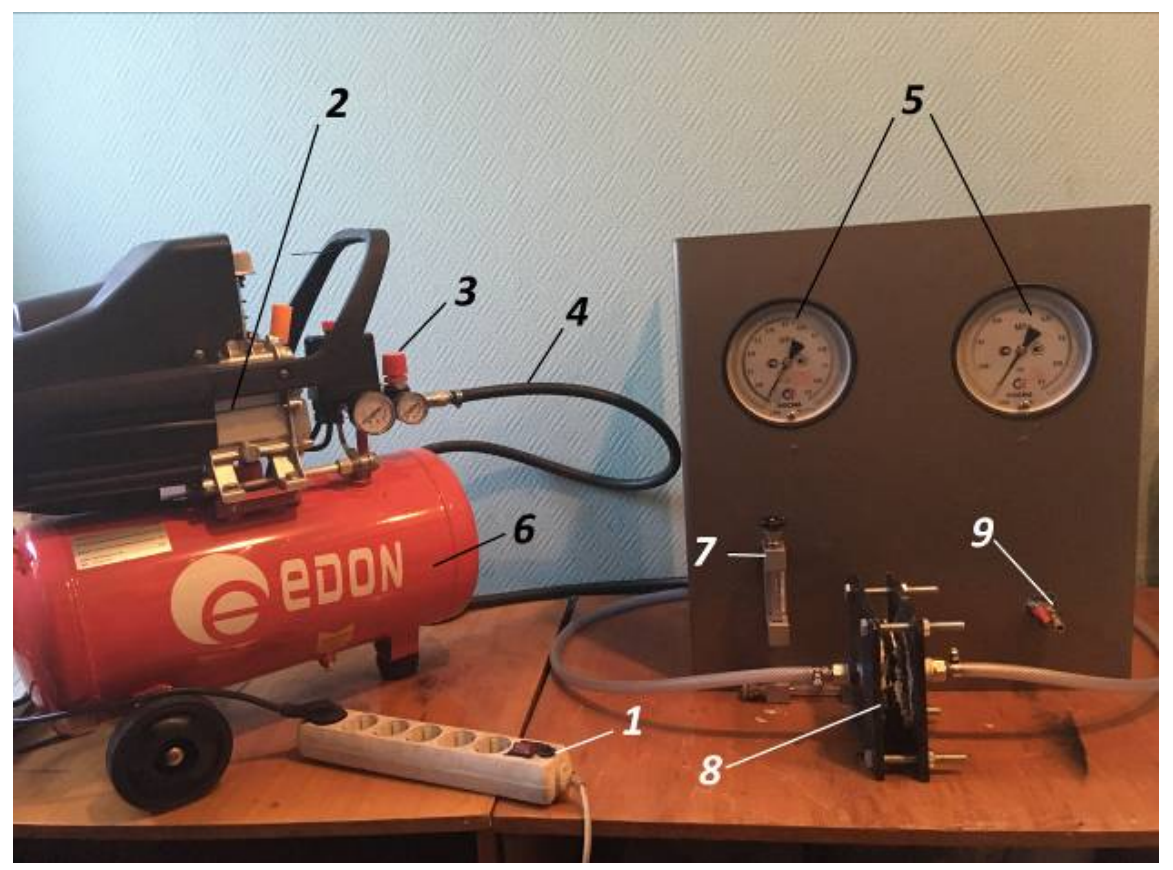

Fig. 2. General view of the installation for determining the core permeability of rocks 1 - power source; 2 - compressor; 3 - pressure valve; 4 - hoses; 5 - manometers; 6 -receiver; 7 - rotameter; 8 - core holder; 9 - outlet faucet.

The results obtained for absolute gas permeability coefficient determination are presented in Table 3. 
Table 3. Values of absolute gas permeability coefficient of rock samples.

\begin{tabular}{|c|c|}
\hline Item No. & Gas permeability coefficient $\left(\right.$ Kpr., $\left.10-3 \mu \mathrm{m}^{2}\right)$ \\
\hline 1 & 0.66 \\
\hline 2 & 0 \\
\hline 3 & 0.463 \\
\hline 4 & 0.387 \\
\hline 5 & 0 \\
\hline 6 & 0.018 \\
\hline 7 & 0 \\
\hline 8 & 0.068 \\
\hline
\end{tabular}

\section{Conclusion}

The measurements carried for absolute permeability coefficient determination witnessed that rock samples are characterized as impermeable (permeability values varied from 0 to $0.66 \mathrm{mD})$.

The study was carried out with the financial support of the Russian Foundation for Basic Research within the framework of the scientific project No. 20-45-420022 r_a.

\section{References}

1. S.A. Khristianovich, Physical and technical problems of mineral resources development (1988)

2. L.A. Nazarov, L.A. Nazarova, Physical and technical problems of mineral resources development (2000)

3. O.V. Tailakov, D.N. Zastrelov, V.O. Tailakov, A.N. Kormin, Gas industry, 12 (2013)

4. O.V. Tailakov, A.I. Smyslov, E.A. Utkaev, GIAB, 9 (2004)

5. S.N. Buzinov, I.D. Umrikhin, Exploration of oil reservoirs and wells (Nedra, Moscow, 1973)

6. GOST 26450.0-85 Mining rocks. General requirements for sampling and preparation of samples to determine reservoir properties (1985)

7. GOST 26450.2-85 Mining rocks. Method for absolute gas permeability coefficient determination during stationary and non-stationary filtration (1985) 